\title{
A NEW PARADIGM OF GOVERNANCE FOR A CARBON-PRICING SYSTEM
}

\author{
S. QUÉRÉ ${ }^{1}$, G. DELMAS-PATTERSON ${ }^{2}$ \& A. BEREZIN ${ }^{3}$ \\ ${ }^{1}$ Département des Sciences de la Terre et de l'Atmosphère, Université du Québec A Montréal, Canada. \\ ${ }^{2}$ Département de Chimie, Université du Québec A Montréal, Canada. \\ ${ }^{3}$ Department of Engineering Physics, McMaster University, Canada.
}

\begin{abstract}
Throughout its life, the United Nations has played a pioneering role in the world of ideas. COP21 - also known as Paris 2015 - shows the path for the United Nations to establish a new governance that will enforce the compliance of a new planetary carbon-pricing system. Maintaining global warming below $2{ }^{\circ} \mathrm{C}$ means implementing an efficient carbon-pricing system, supported by effective measures promoting a green energy transition. A planetary carbon governance yields a number of new insights that include the following: (1) a bonus-malus system with a fixed signal price for carbon, (2) a planetary carbon market that will gather existing regional carbon markets, (3) a hybrid carbon-pricing system linking a carbon tax and a carbon market for advanced countries and (4) a support mechanism for emerging and developing countries to assist them with a carbon-pricing system. This new governance will promote an energy transition plan. In the COP21 context, responsible policymaking requires key characteristics for the enforcement of a successful planetary carbon-pricing system.

Keywords: carbon market, carbon signal-price, greenhouse gases, international governance, United Nations.
\end{abstract}

\section{INTRODUCTION: SEIZING THE OPPORTUNITY OF COP21}

COP21, the $21^{\text {st }}$ Conference of the Parties of the United Nations Framework Convention on Climate Change (UNFCCC), took place in Paris at the end of 2015. The 195 countries represented agreed to provide an international agreement whose main objectives were (1) to maintain global warming below $2{ }^{\circ} \mathrm{C}$, (2) to respect a common but differentiated responsibility as all countries are not equally responsible for climate change and (3) to provide the right of economic growth for each country. In June 2015, the G7 agreed to stop emissions of greenhouse gases (GHG) by the end of the century. The combustion of fossil fuels represents $65 \%$ of greenhouse gases that are responsible for global warming. As in 2015, around $85 \%$ of primary energy in the world comes from fossil energies, a transition to low-carbon energy sources will require a dialogue and collaboration between all the partners: ministries, companies, scientists and citizens.

\section{LIMITING THE EFFECTS OF GLOBAL WARMING}

Planet Earth has warmed up by $0.85^{\circ} \mathrm{C}$ on average since 1880 , the pre-industrial period. A rise in global average temperature of $2{ }^{\circ} \mathrm{C}$ above the pre-industrial period is the maximum of warming advocated by UNFCCC. Otherwise, scenarios with chaotic and unpredictable consequences are expected, especially in terms of water resources, impact on agriculture, air pollution-related healthcare costs and population migration (220,000 refugees in 2014). The World Bank speaks of a 'cascade of cataclysmic changes', which would mainly concern developing countries, because those countries are more vulnerable than others to extreme events or food insecurity driven by climate change. Large areas in Russia, Europe, the United States and Australia have also experimented extreme anomalies in the past years. Heat waves 
lasting several weeks have a devastating effect on human health: more than 70,000 additional deaths occurred in Europe during the hot summer 2003 [1].

It is now proven that anthropogenic GHG are responsible for global warming. However, we still need fossil energies and developing countries have the same right of economic growth as advanced countries got in the past. By 2035, global energy demand could increase by over a third, mainly due to the increase in living standards in China, India and the Middle East [2].

The countries that emit GHG without counterparts are stowaways in economic terms as they degrade the Earth's atmosphere, which is a global public good. Anthropogenic GHG emissions correspond to negative externalities and the societal cost is not taken into account. The present and future generations will have to cope with the negative consequences of climate change impacts that were not paid for in advance. According to the Stern Review, the economic impact of climate change will correspond to 5500 billion of Euros if no action is taken [3]. Even if GHG emissions were stopped now, their adverse effects would persist for many years [4], knowing that adverse effects stand for 'changes in the physical environment or biota resulting from climate change which have significant deleterious effects on the composition, resilience or productivity of natural and managed ecosystems or on the operation of socio-economic systems or on human health and welfare' (UNFCCC).

In 2013, we still observe a huge discrepancy in the energy access: 1.3 billion people have no access to electricity and 2.6 billion are using biomass for current needs [5]. The biggest challenge of the $21^{\text {st }}$ century will be to ensure that everyone has access to clean and sustainable energy and help them overcome poverty.

\section{EXISTING CARBON-PRICING SYSTEMS}

The carbon-pricing policies implemented so far are a carbon tax, a cap-and-trade system and a hybrid policy. Those policies have been chosen by different governments according to their institutional and political contexts which made one or another easier to implement. They both present their own advantages and disadvantages.

\subsection{Carbon tax}

Several countries or provinces have already put in place a carbon tax: Japan, Mexico, France, the United Kingdom, Finland, Sweden, British Columbia, Ireland, Norway, Denmark, Switzerland and Iceland.

The main advantage of a carbon tax is to give a price per tonne equivalent of carbon dioxide emitted (ton $\mathrm{CO}_{2}$ eq). A carbon tax usually applies to the burning of fossil fuels. A tax is easy to implement as an extension of an existing energy tax, and the tax organization - ministry of finances - already exists. For example, it took only 9 months for British Columbia to implement a carbon tax (first public discussion in October 2007, introduction in the provincial budget in February 2008, application of the tax on 1 July 2008).

A carbon tax can provide a double dividend to the governmental budget, because it is not only improving the quality of the environment but also reducing existing taxes, for example, labor and capital income. By getting lower corporation income tax, businesses have more flexibility for investing in efficient energy processes. Revenue neutral by law, the policy from British Columbia, requires that income revenues are used to reduce taxes on individuals and businesses. This new tax had therefore a high social acceptability in British Columbia.

In other countries, like France and Norway, revenues from tax carbon are reinvested in green governmental programs. 
The main disadvantage using a carbon tax remains that it does not quantify the allowable $\mathrm{CO}_{2}$ emissions, thereby allowing this amount to fluctuate.

\subsection{Cap-and-trade systems}

The first cap-and-trade system or carbon market was put in place in the USA to fight against $\mathrm{SO}_{2}$ acid rains in the 1990s ( $\mathrm{SO}_{2}$ cap-and-trade system across USA). By definition, the 'cap' sets a limit in emissions that are lowered over time to reach the target objectives and 'trade' creates a carbon market helping parties innovate to meet their carbon limits. They have been applied to GHG emissions via the Kyoto Protocol (1997), which became effective in 2005. The main polluters China and the USA were not signatories of the Kyoto protocol. In 2011, Canada was the first nation to withdraw from the Kyoto protocol because the country was too far behind in meeting its targets.

\subsubsection{How does a cap-and-trade market work?}

Contrary to a carbon tax, a cap-and-trade market allows to control the ceiling of the anthropogenic GHG emissions. Emission allowances or carbon credits (one ton-equivalent of carbon dioxide), which number is determined by the regulation organisation, are distributed to participants according to their GHG emissions. After a specific period, participants have to demonstrate that they have as many quotas as their number of emissions. If their number of emissions is more important than their number of quotas, then they have to buy the difference of quotas. This process creates an incentive for companies to reduce their emissions and be able to sell rather than buy quotas. The price of each supplementary emission is fixed by the market, through auctioning.

The main principle of a carbon market is to imply more emission reduction for entities where it is cheaper to do so. Basically, they can either choose to invest so that they will less pollute or buy quota emissions via different options. The main cap-and-trade markets are described in the following sections.

\subsubsection{Carbon market under the Kyoto protocol}

As an additional means of meeting the GHG target reductions, countries with commitments under the Kyoto Protocol (Annex B Party) have the choice between three flexibility mechanisms, thereby creating what is now known as the 'carbon market':

1. Emissions trading: to trade units with countries that are over their targets (applicable only to countries that have emission units to spare).

2. The Clean Development Mechanism (CDM): to implement an emission-reduction project in developing countries.

3. Joint Implementation (JI): to earn emission reduction units from an emission-reduction project in another Annex B party.

CDM and JI are the two project-based mechanisms, which firstly fed the international carbon market. They helped countries to reach their GHG target, by enabling them to reduce their emissions through projects outside their national territories. According to the 2009 World Bank report, the revenues delivered by the CDM mechanisms between 2001 and 2012 are estimated around USD 18 billion [6]. EU15 countries have been the main actors of the Kyoto units trading, first trader and first purchaser, under the EU ETS. 


\subsubsection{EU ETS}

The European Union Emissions Trading System (EU ETS) was established in 2003 and effective in 2005. The EU ETS covers more than 11,000 power stations and industrial plants in 31 countries, as well as airlines. Since its beginning, the EU ETS became the largest capand-trade carbon market. On top of using EUA (European Union Allowances), this system also uses CDM and JI mechanisms.

The main disadvantage of a carbon market is to allow carbon pricing to vary. As a consequence, the EU ETS showed a large pricing volatility with a price ranging from 30 EUR ton $\mathrm{CO}_{2}$ eq to 0 at the end of the first period of conformity in 2007. The EU ETS was neutralized by its own weak efficiency compared to the breakthrough of renewable energies supported by favourable tax regimes, which led to an artificial abundance of carbon allowances in circulation.

Revenues generated by auctioning allowances in the EU ETS should be the most promising source of revenues for the European Union. These auctioning revenues could potentially deliver revenues of more than 20 billion EUR per year by 2020 [7]. The question of how the EU ETS revenues should be used for funding climate action is still debated between the European Parliament and the European Commission.

As the largest cap-and-trade system worldwide, the EU ETS went through many trials and errors during the conformity periods and remained complicated. The European Commission presented in July 2015 a legislative proposal to revise the EU ETS for the period after 2020 and the European Parliament defends a renewal of the EU ETS rules in 2019.

\subsubsection{The Chinese carbon markets}

In 2013, China started implementing seven regional carbon markets with the objective of gathering them into a national carbon market from 2017 onwards. The seven cities and provinces are: Beijing, Shanghai, Tianjin, Shenzhen, Guangdong, Hubei and Chongqing. Altogether, those seven regional markets cover $10 \%$ of China GHG emissions and they represent the second larger carbon market after the EU ETS. Each regional market has its own characteristics, which will enable China to conceive the best national carbon market based on the most successful ones. In April 2015, the Chinese carbon markets represented a trading value of USD 122 million.

\subsubsection{The North American carbon markets}

Various regional initiatives have emerged in recent years:

1. The Western Climate Initiative (WCI) is a collaboration between Canadian provinces and US states to reduce global warming and ocean acidification, promote energy efficiency and clean energy investments. Founded in 2007 by five US states (California, Arizona, New Mexico, Washington and Oregon), the WCI gathered one year later 11 members (7 US states - Utah and Montana joined - and 4 Canadian provinces - British Columbia, Quebec, Ontario and Manitoba) and 14 observers (6 US states, 2 Canadian provinces and 6 Mexican states). The WCI partners covered $20 \%$ of the US economy and $76 \%$ of the Canadian economy at that time. Since then, several members left the WCI to join other associations. In November 2011, WCI transitioned into WCI, Inc., a non-profit corporation formed to provide administrative and technical assistance to support the implementation of state and provincial GHG emissions trading programs. Current members are British Columbia, California and Quebec. The WCI, Inc. has released two major reports, 
the Design Recommendations for a Cap-and-Trade Program (2008) and the Design for the WCI Regional (2010). Those reports defined the roadmap, as well the structure and functioning of the GHG trading systems. Members could then use those reports to develop their own carbon market and based on a common platform, the markets had the possibility to be linked together. In 2012, Quebec and California decided to follow the roadmap designed by the WCI, Inc. In 2013, both Quebec and California created their own carbon markets: the Quebec cap-and-trade system for GHG emission allowances (Système de plafonnement et d'échange de droits d'émission de gaz à effet de serre du Québec or SPEDE) and the California cap-and-trade program. In 2014, Québec and California linked their markets and in March 2015, the common auctions had raised in total about USD 1.6 billion and 245 million, respectively. In April 2015, Ontario has finally settled on a cap-and-trade market that will be linked with the existing systems in Quebec and California.

2. The Regional Greenhouse Gas Initiative (RGGI) was the first American cap-and-trade system developed in the North East of the United States in 2009. The RGGI gathered initially 10 states: Connecticut, Delaware, Maine, Maryland, Massachusetts, New Hampshire, New York, Rhode Island, Vermont and New Jersey. Profits auctions are reinvested in energy efficiency and renewable energy projects. These programs encourage innovation and help create employment in the sector of clean energy. Since the first auction in 2009, the revenues have reached around USD 2.9 billion (April 2015).

\subsection{Hybrid systems}

A hybrid system collects revenues that come from a cap-and trade market and from a carbon tax. This system is inspired from Western Europe and Scandinavian models: United Kingdom, France, Ireland, Iceland, Switzerland, Norway, Sweden and Denmark. Countries with a hybrid system have decreased successfully their GHG emissions. Norway, Denmark and Sweden intend to become carbon neutral in 2050.

\section{OBJECTIVE 2100: A NEW GOVERNANCE FOR A CARBON-PRICING MARKET}

Fighting against climate change does not mean slowing down the world economic growth. Our challenge is to find policies that will help to reduce GHGs at the lowest possible cost.

Our solution is an international governance with a leadership in strategy and operation. We need a new paradigm of governance with the objective of zero anthropogenic GHG emissions by 2100 . Intermediate milestones are the creation of an international carbon market that will gather all the existing sub-markets, of incentives for national hybrid systems designed for advances countries and of support for a green energy transition for developing countries. As fossil energy producers will have to find new revenue sources, innovative renewable solutions are needed now more than ever.

We therefore propose a new organisation created by the UNFCCC, under aegis of the World Bank and of the International Monetary Fund (IMF). This organisation will be based on a new paradigm of governance, which starts by giving a signal-price to carbon.

\subsection{Creation of a bonus-malus system}

A fixed carbon price can be implemented via a bonus-malus system, which is based on the average emissions per head per year, in which countries emitting more than the world average 
should pay a penalty (they are polluters), and countries below this bar would receive a bonus (they are beneficiaries). The Climate Economics Chair of Paris proposed this solution as the world average (6.3 ton/capita in 2011) can hide a huge disparity: 29.5 ton for an Australian and 0.6 ton for a Congolese [8]. A bonus-malus system provides a balance between the contributions coming from the biggest polluters ('penalty' countries) and the subsidies going to beneficiary countries ('bonus' countries).

\subsubsection{Common but differentiated responsibility}

The Kyoto Protocol in 1997 drew a distinction between the countries considered historical polluters - and therefore responsible for a part of the current GHG concentration in the atmosphere - such as USA, EU and Japan and the emerging and developing countries such as India and China. Meanwhile, China exceeded the $\mathrm{CO}_{2}$ emission rate of USA. This bonusmalus system would count for both past and present polluter responsibilities.

\subsubsection{A signal-price for carbon}

What do we call a signal-price?

The price of a product or a service depends on supply and demand. By adding signal, we send a strong message to all citizens of our planet to make us realise that our actions have consequences on carbon emissions, and therefore must be paid for. Finally, a fixed or signal-price means that all the parties agree to adopt a fixed carbon price on a global scale.

The Climate Economics Chair of Paris suggests a price of $7.5 \mathrm{USD} \mathrm{CO}_{2}$ eq per ton given before 2020. This price has been specifically chosen because the sum of all the contributions will generate around USD 100 billion per year (a different price would provide a different sum) (cf. Fig. 1). This amount corresponds to the funding pledged during Copenhagen 2009 and Cancun 2010 for the Green Climate Fund. But so far, the money has not materialised.

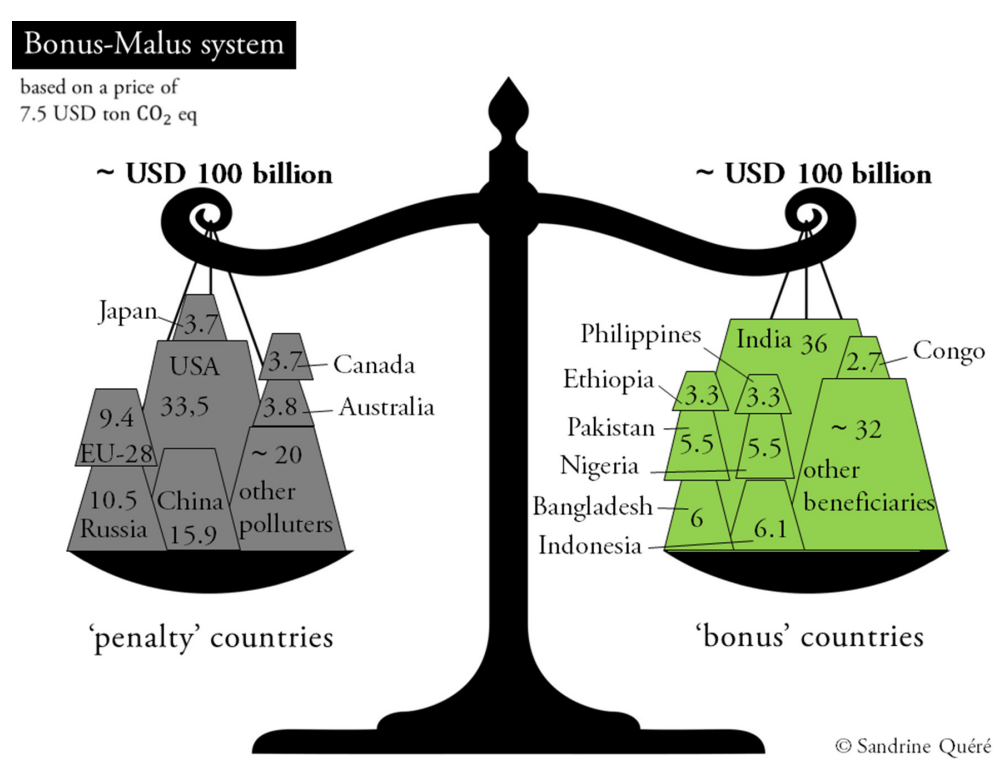

Figure 1: Bonus-malus system: balance between the sum of contributions coming from the main polluters and the sum of subsidies going to beneficiaries countries. 


\subsubsection{Revenues of 100 billion USD per year}

With the reference year of 2011, USA, China, Russia and Europe should be the most contributors, with respectively 33.5, 15.9, 10.5 and 9.4 billion US dollars to be paid annually (cf. Table 1). The most beneficiary countries should be India (\$36 billion), Indonesia ( $\$ 6.1$ billion), Bangladesh ( $\$ 6$ billion), Pakistan ( $\$ 5.5$ billion) and Nigeria ( $\$ 5.5$ billion) (cf. Table 2).

To calculate the bonus-malus for each country, we employed the following formula using the world average $\mathrm{CO}_{2}$ emissions per capita (6.3 ton/capita in 2011):

$\mathrm{BM}(\$)=\mid($ Em. $/$ Cap. $)-6.3 \mid *$ Pop.* Price

with Price $=7.5 \mathrm{USD} \mathrm{CO}_{2}$ eq per tonne

It is noteworthy that there is an almost balance between the contributions due to the biggest polluters and the subsidies received by beneficiary countries: these 100 billion bonus-malus correspond to the amount promised during COP14 (Copenhagen) and COP15 (Cancun). Advanced countries committed to jointly mobilise USD 100 billion a year by 2020 for international climate actions as part of the Green Climate Fund, including North-South financial transfers. So far, neither with public, nor with private funds, have advanced countries been able to fulfil this commitment. How to raise such an amount of funds remained the crucial question during the next Conferences of the Parties.

Given the urgency of a credible and ambitious agreement, we suggest that we adopt a price around 7-8 USD $\mathrm{CO}_{2}$ eq per tonne as soon as possible. This relatively cheap price will facilitate the acceptance of the mechanism. The key being to enable a transnational market causing massive financial transfers between the North and the South. A gradual increase per year till 2020 could then take into account inflation and endorse a binding carbon market.

These USD 100 billion could finance the Green Climate Fund for international climate actions and local initiatives (e.g., local currencies). For developing countries, the World Bank

Table 1: Total GHG emissions for largest emitters (excluding agriculture and forestry)

\begin{tabular}{|c|c|c|c|c|}
\hline Countries & $\begin{array}{l}\text { Total emissions } \\
\left(\mathrm{Mt} \mathrm{CO}_{2} \mathrm{eq}\right) \\
\text { (Tot. Em.) }\end{array}$ & $\begin{array}{c}\text { Population } \\
\text { (millions) } \\
\text { (Pop.) }\end{array}$ & $\begin{array}{c}\text { Emissions per capita } \\
\left(\mathrm{t} \mathrm{CO}_{2} \text { eq }\right) \\
\text { (Em./Cap.) }\end{array}$ & $\begin{array}{c}\text { Bonus-Malus } \\
\text { (\$ million) } \\
(\mathrm{BM})\end{array}$ \\
\hline USA & 6,436 & 312 & 20.6 & 33,528 \\
\hline China & 10,596 & 1,344 & 7.9 & 15,966 \\
\hline Russia & 2,310 & 143 & 16.15 & 10,568 \\
\hline EU-28 & 4,430 & 503 & 8.8 & 9,458 \\
\hline Australia & 648 & 22 & 29.5 & 3,820 \\
\hline Canada & 714 & 34 & 21 & 3,748 \\
\hline Japan & 1,302 & 128 & 10.2 & 3,717 \\
\hline South Korea & 687 & 50 & 13.7 & 2,790 \\
\hline Saudi Arabia & 498 & 28 & 17.8 & 2,412 \\
\hline Iran & 707 & 75 & 9.4 & 1,759 \\
\hline Others & 4,546 & 399 & 11.4 & 15,242 \\
\hline Total polluters & 32,874 & 3,038 & 10.8 & 103,009 \\
\hline World & 43,413 & 6,903 & 6.3 & 0 \\
\hline
\end{tabular}

Source: World Resource Institute 2011. 
Table 2: Total GHG emissions for beneficiary countries (excluding agriculture and forestry)

\begin{tabular}{|c|c|c|c|c|}
\hline Countries & $\begin{array}{l}\text { Total emissions } \\
\left(\mathrm{Mt} \mathrm{CO}_{2} \text { eq) }\right. \\
\text { (Tot. Em.) }\end{array}$ & $\begin{array}{l}\text { Population } \\
\text { (millions) } \\
\text { (pop.) }\end{array}$ & $\begin{array}{c}\text { Emissions per capita } \\
\text { (t CO } \mathrm{CO}_{2} \text { eq } \\
\text { (Em./Cap.) }\end{array}$ & $\begin{array}{c}\text { Bonus-Malus } \\
\text { (\$ million) } \\
(\mathrm{BM})\end{array}$ \\
\hline India & 2,883 & 1,221 & 2.4 & 36,070 \\
\hline Indonesia & 723 & 244 & 3.0 & 6,106 \\
\hline Bangladesh & 156 & 153 & 1.0 & 6,059 \\
\hline Pakistan & 320 & 176 & 1.8 & 5,521 \\
\hline Nigeria & 297 & 164 & 1.8 & 5,521 \\
\hline Ethiopia & 116 & 89 & 1.3 & 3,335 \\
\hline Philippines & 155 & 95 & 1.6 & 3,326 \\
\hline Congo & 38 & 64 & 0.6 & 2,739 \\
\hline Vietnam & 256 & 88 & 2.9 & 2,238 \\
\hline Brazil & 974 & 195 & 5 & 1,901 \\
\hline Tanzania & 71 & 46 & 1.5 & 1,641 \\
\hline Others & 5,510 & 1,524 & 3.6 & 30,684 \\
\hline Total beneficiaries & 10,525 & 3,776 & 2.8 & 101,379 \\
\hline
\end{tabular}

Source: World Resource Institute 2011.

estimates costs of about USD 140-175 billion for mitigation and about USD 30-100 billion for adaptation [9].

Jim Yong Lim, CEO of World Bank, urged investors to get involved into the green bond market to raise funds dedicated to climate mitigation, adaptation and other environment-friendly projects to mobilise USD 50 billion by the time of Paris 2015 [10].

The UE and the USA with, respectively, the EU ETS and the Clean Power Plan are already self-declared leaders in fighting climate change. According to Christian de Perthuis, president of the Climate Economics Chair of Paris, the key to a climate agreement is in China because if the Chinese government supports the bonus-malus system, then it would be very difficult for the other blocks, including Russia, to disagree. This agreement would be the direct following of the US-China climate accord signed in November 2014, stating that the US committed to a reduction in emissions between 26 and $28 \%$ by 2025 compared to 2005 , and that China agreed to stop its emissions from growing by 2030.

We are therefore able to provide a credible and audacious solution. We note that three main emitters out of four already have carbon markets (USA, EU and China). The fourth emitter, Russia, is a fossil-fuel exporting country. We can thereby propose the bold following solution:

1. The bonus-malus system will be funded via the gathering of the main existing carbon markets.

2. The remaining funds will come from the other emitters like Canada and Australia, from fossil-fuel exporting countries (Russia and Saudi Arabia in particular) and from Asian emerging emitters such as Japan and South Korea. 


\subsection{An international carbon-pricing system}

We suggest to use the experience gained with the implementation of the international carbon market after the Kyoto protocol, and to build on it.

\subsubsection{A global-scale carbon market}

A successful global carbon market is the one that will be able to gather the international carbon market with the EU ETS, the Chinese market and the American markets, which are the main existing carbon markets. The solution is a successful merge of a new international carbon market with a fixed carbon price. This new carbon governance will send a strong signal of hope to the planet.

Compatible registries and requirements are needed to create a global carbon market. It starts with diplomacy in communication between different systems. Quebec and California were the first ones to link their carbon markets in November 2014. This transnational example provides already hope as that linkage had to overcome two different juridical settings, the common law and civil code. Applying a fixed carbon price is one of the best solutions to standardise markets.

The enforcement of the rules could be relocated at the national levels. For example, in the case of the EU ETS, the GHG emission rules are based on a consensus between the executive power - the European Council and the European Commission - and the legislative power the European Parliament. Commitments are made at the European community level and law application at the national level via ETS regulation. Dissuasive fines enforce the credibility of the EU ETS regulation.

4.2.2 A hybrid system at the national level for advanced countries

Advanced countries that do not have implemented any carbon pricing yet could adopt a hybrid system, based on the experiences made in other countries. A hybrid system, based on a carbon tax and on a fixed carbon pricing market, presents several advantages:

1. Most of the GHG are taken into account as the tax and carbon market systems do not apply to the same GHG.

2. Most of the territory is covered as a carbon tax corresponds to diffuse emissions within the perimeter of a territory, whereas a carbon market applies mainly to the larger emitters of a country.

3. Financial efficiency of the hybrid system. The carbon market system will generate revenues that can be used for green national climate actions and the Green Climate Fund, whereas a carbon tax can create income within a short or medium term, which could be redistributed to individuals and businesses. In British Columbia, the carbon tax provides $3 \%$ of the provincial budget [11].

\subsubsection{Support for a carbon-pricing system for developing countries}

The international governance should play an important role to provide integrated knowledge and innovative solutions for transformation towards sustainable development in developing countries.

The new organisation will ensure that revenue distributions reach developing countries and regions that will lack revenues from fossil energies. Fossil oil producers will need specific support, as discussed below. 
To develop their own carbon-pricing system, emerging and developing countries will have the choice between joining existing carbon-pricing systems and using climate actions as explained in the following transition plan.

\section{PRINCIPLES OF GOVERNANCE}

This new governance is based on a few principles:

\subsection{A stable carbon pricing for certitude in best investment decisions}

This global-scale market with a fixed carbon price would automatically equalize the price of a ton equivalent $\mathrm{CO}_{2}$ between countries or regions. There will be no more need for auctions, neither 'gambling' on a carbon market. A fixed carbon pricing will enable the stability needed to establish a global carbon market while gathering existing regional carbon markets.

Implementing an international carbon market with a signal-price starting around US\$7-8 will will simplify all the regulation systems. Stable price allows certainty and therefore best investment decisions. In an international context, carbon markets must be effective to obtain an agreement between countries.

A stable pricing has lots of advantages compared to a volatile price given with a trade market. For example, the EU ETS decided to use backloading of allowances (temporary withholding of auctioning allowances) before transferring them back into the market stability reserve as too many quotas were available and therefore lost their incentive value. A stable price will provide some certainty where uncertainty exists in the growth production forecast, in renewable energy investments and in future energy efficiency assessment.

Most of studies foresee that advanced economies like Western Europe and Japan would have to pay for their emission rights. There is actually no consensus concerning emergent economies. On one hand, those countries represent a huge economic potential, which implies buying emission rights [12]. On the other hand, as the emitted carbon level by unit of production is important, the possibility of energetic efficiency is important, and therefore the opportunity of selling emission rights [13]. It can, however, be expected that emerging and developing countries are going to reduce emissions much more cheaply than developed countries. For example, if China and India had access to the European and Japanese technologies, they could therefore reduce drastically their emissions by increasing their energetic efficiency and decreasing their use of coal. The carbon dioxide cost could be lowered by half if a worldwide pricing was established [14].

\subsection{Fairness of the system}

Fossil fuel producing countries like Algeria, Russia, Congo and Nigeria will need support in order to find new revenue sources. Among them, Congo and Nigeria are beneficiaries from the bonus-malus system. In its Decarbonizing Development review, the World Bank is determined to transform leaders of those countries into 'allies rather than opponents' and calls for establishing compensation and pilot projects in these impacted areas [15].

Financial costs for clean energies can represent an obstacle. Solutions could be to supply contracts with sober carbon energy or green certificates to help investments in sectors with funding difficulties. We need to implement stable policies that are going to facilitate access to investment while minimizing the risk of investors. 
The 'carbon leakage' threat (relocating carbon emissions) could be stopped by enlarging the carbon market. China is shutting down its coal-fired plants in Beijing and opening new factories in other provinces. Relocating GHG emissions, like what China is presently doing, is just moving the problem, and that is why the EU ETS provides a certain amount of free quotas to big polluters.

Important areas of both Bangladesh and the Netherlands are under sea level. The Netherlands have enough national funding to build a dam around their country. Even if the Bangladesh does not have enough national finances to preserve its territory from the sea, that country is a beneficiary from the bonus-malus system and therefore could receive support from international collaboration. Indonesia is also a beneficiary. Indonesian islands are sensitive to extreme climate and will beneficiate from the bonus-malus funding. All in all, the bonusmalus system is fair in redistributing funds among countries that will need it the most.

\subsection{Transition energy plan}

Stopping GHG anthropogenic emissions by the end of this century means establishing specific milestones by going backwards:

- 2100: ratio of non-fossil energy (nuclear and renewable) to total primary energy of $100 \%$

- 2050: ratio of non-fossil energy of $50 \%$

- 2035: ratio of non-fossil energy of $35 \%$

- 2025: ratio of non-fossil energy of $25 \%$

- 2015: ratio of non-fossil energy of $15 \%$ (ratio reached in 2015)

These progressive goals will only be achieved through global synergy between all countries. With USD 100 billion generated per year from now on, we could already finance international climate actions. This would provide much-needed investment in renewable energy, sustainable development and new green jobs.

Without clear objectives and without proper methods for our energy source renewals, these goals will never be achieved. Firstly, it will be necessary to reduce the power consumption by restraining demand and improving energy efficiency. At the current rate of energy consumption, the reserves of oil, natural gas and coal represent about 51, 61 and 109 years, respectively. Secondly, achieving the zero GHG emissions goal for 2100 means the end of fossil fuel subsidies. Fossil fuels are cheap only because they are stowaways and receive subsidies from governments. Several countries such as Ghana, Ukraine, Iran and Indonesia are already heading towards that end, often more for financial reasons than for climate change. In the best case, the money not put into fuel subsidies has been transferred to the poor or social security extensions. In Ghana, for example, primary school became free. The use of fossil fuels should be gradually replaced by the use of low carbon and non-fossil energies. For example, the oil company Total is now developing its natural gas sources as natural gas combustion provides $50 \%$ less carbon dioxide than oil combustion.

Transition to a post-fossil fuel world of clean energies will require major investments and will not occur if fossil oil remains the most used energy for transportation. In addition, the solution will be an energy mix due to uncertainties in future energetic developments and also because there is not a single energy that alone can meet all of our needs. Renewable energy sources, biomass and hydroelectric are already being exploited on a large scale. Biomass can be used in biogas and biofuels. Hydropower has already used the best sites for locating dams 
at good prices. Wind and solar-based systems are probably the solutions for this century. However, we will need previously to improve their reliability (reduced due to intermittency), as well as their ability to store energy. Nuclear power still faces concerns about safety, nuclear waste and potential weapon proliferation, which have been lately improved by the fourth generation of nuclear power concepts [16].

The transition energy plan will create many new green jobs as we must build on the creativity of the human brain to offer new solutions in energy efficiency: re-use of goods; electric cars with greater autonomy; fuel cells; liquid hydrogen; other alternative energy sources like LENR (Low-Energy Nuclear Reactions). LENR or 'cold fusion' is currently studied in a number of laboratories across the world. Contrary to existing nuclear energy technology (fission reactors), LENR systems do not produce radioactive waste.

According to IMF, living in a zero emission world is possible for 2100. The IMF defends investments in green building and transportation. Towns will be more efficient, denser, better linked by public transportation. Starting now, towns in developing countries should grow around public transportation networks. And densifying cities does not necessarily mean transforming them into ghettos.

The energy use and industrial production represent two thirds of GHG emissions, whereas forest and land use account for one third. Land use could be turned into carbon wells (carbon sequestration or reforestation). We therefore need to develop new technologies for carbon capture and storage or sequestration (CSS), for example, by storing it underground or in carbonated bricks. IMF is considering parts of negative emission zones dedicated to GHG absorption. This project could lead to land use conflicts and new measures will be implemented to verify that populations are not despoiled. Limiting deforestation would be one of the cheapest way to reduce carbon emission and should become a priority through Reducing Emissions from Deforestation and Degradation (REDD) projects.

Finally, a great advantage of an international signal price is that we will have the possibility of knowing how much we pollute and how much we have to pay for it. The theory of change here is that this will motivate us to consume less. For example, since British Columbia introduced a carbon tax in 2008, fuel use dropped by $16 \%$, whereas it increased by $3 \%$ in the rest of Canada.

\subsection{Planetary carbon market operational in 2020}

Beyond 2020, the bonus-malus system with a fixed price will be evaluated, country per country. The UN governance will therefore be able to choose between keeping a bonus-malus system funded by the gathering of regional carbon markets or replacing it with a global capand-trade carbon market that allows carbon price to vary within a specific range and with a bottom price.

According to the success of this new governance, countries will have the choice of either joining the planetary carbon market, implementing a hybrid system or developing their own carbon-pricing system.

\subsection{Characteristics of a successful planetary carbon pricing}

We have established the following key characteristics for a successful planetary carbon-pricing system: 
1. Global transparency: Define with a precise and equitable system the initial allocation of quotas. Countries commit to a specific percentage of GHG emission reduction.

2. Efficiency: Ensure an efficient system for emission measuring and put in place registers to track the follow up of all quota transactions. Clear regulation rules. Developing an MRV system (Monitoring, Reporting and Verification) for all participants. Assessments of countries' commitments every 4 or 5 years.

3. Fairness: Develop renewable energies and promote sustainable development. Develop pilot projects for fossil fuel producers to support them in a transition towards a postfossil world.

4. Flexibility: Authorise flexible mechanisms through compensation credit use and appropriate rules for borrowing and backloading. Parameters of environmental policies are going to change with scientific innovations and varying estimates of fossil fuels and the world economy. We must be able to allow companies to adjust their reductions in response to these various parameters.

5. Velocity: In its race against time fighting climate change, gathering the existing regional carbon markets will save both time and energy from their respective administrations.

6. Intentionality: Set the objective of being operational by 2020. Beyond 2020, countries should have the choice between linking to the planetary carbon-pricing system or implementing their own carbon-pricing system.

7. Trust: Implement a stable carbon market via a bonus-malus system with a fixed carbon price. Help countries in their commitments in GHG emission reductions.

8. Education and communication: Educate citizens. Most people do not take the time to inform themselves about climate change or they are simply not interested. Climate change still seems too abstract for most people.

\section{CONCLUSION}

An international governance with a strong leadership in strategy and operation should reach its objectives of zero GHG anthropogenic emissions by 2100. A planetary carbon market with focussed actions should be implemented quickly to motivate regional markets to gather into a cooperative market. We propose a bonus-malus system to ensure that the stowaways pay for their past and current atmosphere pollution. It is expected that this bonus-malus system with a yearly increasing carbon price will provide around USD 100 billion the first year and subsequently more the following years. The funding will be provided by the gathering of the main regional carbon markets. Additional funds will be supplied by large emitters like Russia, Australia, Canada, Japan, South Korea and Saudi Arabia. The new governance will therefore be able to restore advanced countries' integrity by financing climate actions through the Green Climate Fund. North-south financial transfers will help developing countries in their mitigation and adaptation efforts. An important part of this funding will help the countries whose economy is drastically linked to fossil fuel extraction to meet their energetic transition towards more sober carbon revenue sources. Priorities will be put on developing renewable energies and improving energetic efficiency. On top of the planetary carbon market, advanced countries could adopt a hybrid system and developing countries will have the choice of joining the planetary carbon-pricing system or developing their own green system. A successful planetary carbon market is ensured if the international governance follows basic principles: global transparency, efficiency, fairness, flexibility, velocity, intentionality, efficiency, trust and public education.

Our humanity's objective is not only to stop anthropogenic GHG emissions by 2100 but also to ensure a decent life and an energy access for all. A global carbon pricing system could be the first planetary measure for a greener future for all the inhabitants of our planet Earth. 


\section{REFERENCES}

[1] Robine, J.M., Cheung, S.L., Le Roy, S., Van Oyen, H., Griffiths, C., et al., Death toll exceeded 70,000 in Europe during the summer of 2003. C R Biol, 331, pp. 171-175, 2008. doi: http://dx.doi.org/10.1016/j.crvi.2007.12.001

[2] International Energy Agency, World Energy Outlook, Paris, France: International Energy Agency, 2012.

[3] Stern, N., The economics of climate change: the Stern review. London, HM Treasury, pp. 712, 2006.

[4] Jones, B., Keen, M., Norregaard, J. \& Strand, J., Climate change: economic impact and policy responses. International Monetary Fund. World Economic Outlook, pp. 53-65, 2007.

[5] International Energy Agency, World Energy Outlook, Paris, France: International Energy Agency, pp. 12, 2013.

[6] The World Bank, The World Bank Annual Report 2009, pp. 68, 2009.

[7] European Commission. Scaling up international climate finance after 2012. Commission Staff Working Document, European Commission, Brussels, pp. 46, 2011.

[8] De Perthuis, C., Jouvet, P.-A., Trotignon, R., Solier, B., Meurisse, B. \& Quemin, S., Economic instruments and the 2015 Paris Climate Conference: the catalyst of carbon pricing. Climate Economics Chair, pp. 12, 2015.

[9] The World Bank, The World Bank Annual Report 2011, pp. 43, 2011.

[10] World Economic Forum, Davos, Switzerland, pp. 60, 2014.

[11] Harrison, K., The political economy of British Columbia's carbon tax. OECD Environment Working Papers, pp. 23, 2013.

[12] Den Elzen, M., Lucas, P. \& van Vuuren, D., Abatement costs of post-Kyoto climate regimes. Energy Policy, 33(16), pp. 2138-2151, 2005. doi: http://dx.doi.org/10.1016/j. enpol.2004.04.012

[13] Persson, T.A., Azar, C. \& Lindgren, K., Allocation of $\mathrm{CO}_{2}$ emission permits - economic incentives for emission reductions in developing countries. Energy Policy, 34(14), pp. 1889-1899, 2006. doi: http://dx.doi.org/10.1016/j.enpol.2005.02.001

[14] Flachsland, C., Marschinski, R. \& Edenhofer, O., To link or not to link: Benefits and disadvantages of linking cap-and-trade systems. Climate Policy, 9(4), pp. 358-372, 2009. doi: http://dx.doi.org/10.3763/cpol.2009.0626

[15] Fay, M., Hallegatte, S., Vogt-Schilb, A., Rozenberg, J. \& Narloch, U., Decarbonizing development, World Bank Group, 2015.

[16] Till, C.E. \& Chang, Y., I., Plentiful Energy: The Story of the Integral Fast Reactor United States, CreateSpace Independent Publishing Platform, pp. 116, 2011. 